\title{
Application of photovoltaic cells as a source of energy in unmanned aerial vehicle (UAV) - case study
}

\author{
Karolina Papis ${ }^{1, *}$, Rafat Figaj ${ }^{1}$, Jakub Kuś ${ }^{1}$, Maciej Żołądek ${ }^{1}$ and Michat Zając ${ }^{1}$ \\ ${ }^{1}$ AGH University of Science and Technology, Cracow, Poland
}

\begin{abstract}
During last years, renewable energy sources (RES) find their way into the transportation industry. Among the units which may be powered directly with renewable energy, the UAVs (unmanned aerial vehicles) market is undergoing a rapid development. In this case mainly the solar energy is used. Photovoltaic modules are mainly located on the wings, so it is often necessary to use flexible PV cells which have lower efficiency than the flat ones. This study proves that airfoil geometry modifications by partial flattening are not beneficial from the aerodynamic point of view. The lower energy conversion on photovoltaic panels must be balanced by energy storage and energy management systems. The performance of exemplary installation mounted on AGH Solar Plane has been modelled with TRNSYS software. Obtained results allowed to establish the amount of produced, stored and used energy in six different months.
\end{abstract}

\section{Introduction}

Last years have been a period of rapid shift concerning the main factors which affect development of new technologies. Beside economic performance the environmental impact is emerging as a crucial aspect deciding which technology gets attention of researchers community and business entities. Especially international commitments progressively enforcing more restrictive policy in the field of greenhouse emmission are the ones of increasing importance.

\subsection{E-mobility}

In accordance with that change, renewable energy sector is at its peak. Notably, renewable energy sources find their way into the transportation industry, which is responsible for approximately $14 \%$ of global $\mathrm{CO}_{2}$ emmission (2017). [1] Efforts of improving transportation's environmental friendliness stimulate development of diverse electric vehicles and thus establishes a new sector referred to as e-mobility. As there is no need to use internal combustion engines in electric vehicles, the noise pollution is also decreased. [2] Some of the vehicles are powered by the energy from electrochemical storage systems such as batteries. There is also a smaller grop of vehicles powered directly from the renewable energy sources. Deployment of this promising alternative reduces greenhouse emmission and decreases the fossil fuels consumption. [1] Additionally, those devices act as energy storage system of high mobility. [3] Among the other RES, solar energy is the well-established one. One of its main application is direct conversion of solar irradiation into the electric power realised with the photovoltaic cells. Compared to the use in immobile systems, PV pannels face other challenges deciding which parameters are crucial considering performance of the device. The main factors which must be taken into account are e.g. limited space and usually high power required to operate the vehicle. [4] Due to these factors PV arrays used in transportation must meet such criteria as small weight, reduced surface and high efficiency. [4]

\subsection{Solar-powered aircrafts}

Among the units which may be powered directly with renewable energy, the aerial vehicles market is undergoing a rapid development. History of solar aircrafts reaches as far as 1974, when the prototype airplane Sunrise I was introduced by Astro Flight Inc, demonstrating the possibility of powering aerial vehicle exclusively with solar energy. [5] Sunrise $I$ had the weight of $12.3 \mathrm{~kg}$ and its wingspan reached $9.8 \mathrm{~m}$. [5] In case of the next model, Sunrise II, weight was decreased by $13 \%$ and its power was greater by $33 \%$ compared to the previous prototype. [6] Next pioneer aircrafts Gossamer Penguin and Solar Challenger - were designed by AeroVironment Inc. [6] Further models followed, leading to the first prototype of high-altitude airplain called the Pathfinder. [7] This continuously improved unit reached the record altitude of $24.4 \mathrm{~km}$ as the model variation known under the name of Pathfinder Plus, with the wingspan of $36.9 \mathrm{~m}$. [5] One of the remarkable milestones in the development of solar aircraft was the first intercontinental flight from Switzerland to Morocco in 2011. [5] This was achieved by HB-SIA, a prototype

Corresponding author: papis@agh.edu.pl 
created by Solar Impulse SA. HB-SIA was equipped with energy storage system comprised of $400 \mathrm{~kg}$ of lithium batteries and harvested the solar energy with PV arrays of around 12000 cells. [5] At this point a flight around world was also realised by solar aircraft. [8] Among the other aerial vehicles especially the UAVs (unmanned aerial vehicles) gained a significant interest. This is a case because of the high utility of those devices and numerous applications in both civil and military sectors. Incorporation of the RES into the UAVs technology is challenging and requires consideration of many additional constraints. Solar energy is an uncontrollable source dependent on the weather conditions and its application in aerial vehicles must be supported with energy storage. [4] Space allocated to energy storage is limited, as well as its weight. Energy storage coupled with RES also introduces auxiliary elements necessary to generate, transfer and transform energy. These parts are not only the additional weight load, but also sources of energy losses. [4] In case of units which have PV modules located on the wings, it is often necessary to use flexible PV cells. Encapsulation of bent cells conducted in order to achieve the shape compatible with airfoil is a process which could deteriorate the efficiency of PV cells. [9] On the other hand, without bending of PV cells, it is difficult to manufacture the airfoil profile characterised by desired aerodynamic properties. [9] Two of the forces generated by airflow around the wings are lift and drag. Since lift force is dependent on square of the speed, increased speed results in greater lift force. This is an important relation, because solar aircrafts usually achieve lower speeds than conventional ones and consequently obtain lower lift force opposing the gravity. [10] The analysis described in this study proves that, the modification of shape of wing profile airfoil is not beneficial from aerodynamic point of view.

\subsection{Dynamic simulations in TRNSYS}

Performance of energy systems, especially bassed on renewable sources, depends on various factors. To evaluate their operating parameters the dynami cal simulations should be provided. TRNSYS (TRaNsient SYstem Simulation program) is a software based on the graphical components which is commonly used to simulate operation of transient systems such as renewable energy installations. This program includes library with ready-to-use numerous components which represents single elements of systems (like photovoltaic pannels, turbines, boilers, fans etc). Moreover there is a possibility to implement additional component defined by user and spread the functionality of software. The operation of individual elements is based on the set of parameters (for example: efficiency, capacity, temperature difference). The individual components are linked together and the data transfer is stated between them. All the mathematical equations that describe the physical phenomena are hidden inside the object and the calculation steps are invisible for user. Only the final results are shown, so the components are called 'black box' [11]. The great advantage of this software is availability of weather data for places from around the world. Therefore the operation of system components may be dependent to local irradiance, temperature, rain fall, wind speed. This essential in case of renerwable energy systems. TRNSYS allows to carry out the variant analysis without need of rebuilding the whole model.

\section{Analysed aircraft}

This case study focus on the aircraft 'Cyjnan' built by students from AGH Solar Plane team. This plane is a third construction with wingspawn $3.8 \mathrm{~m}$, total length $2.1 \mathrm{~m}$ (presented in figure 1.) and mass $3.6 \mathrm{~kg}$.

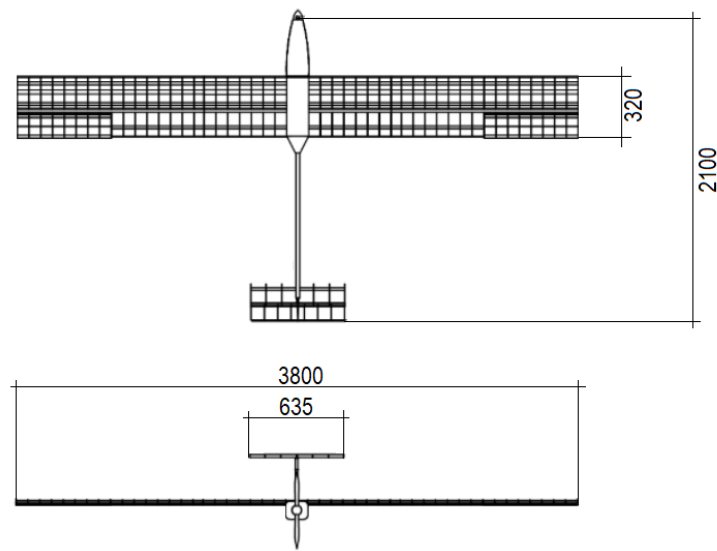

Fig. 1. Main dimensions of analysed solar plane.

In comparison to previous model (with the same dimensions), the significant mass reduction (about $0.9 \mathrm{~kg}$ ) was obtained due to application of component materials: resins, carbon fibers, glas fibers, and extruded polystyrene foam. These materials are characterized by durability and ease of giving any shape. This allowed consideration of application of concave-convex airfoils, even with modifications of upper surface.

\subsection{Aerodynamical properties}

The essential problem of aircraft design is to provide the values of aerodynamical properties as high as possible. The significant impact on lift and drag has got the profile of wing. In this case, as reference profile the Wortmann FX-60-100 has been analysed with usage XFOIL software. Then, to determine the influence of the partially flat wings on the aerodynamical parameters three new geometries has been examined: with 3 and 6 flat surfaces (see figure 2). The number of flat plates was limited by photovoltaic cells dimensions.

a)

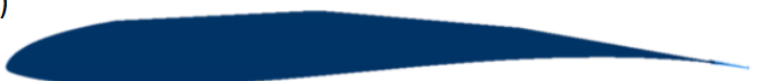

c)

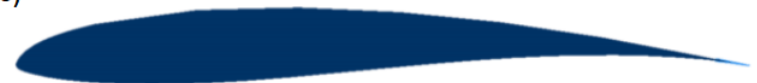

Fig. 2. Shapes of modified airfoils with a) 3, b) 6 flat surfaces. 
The flow around bodies placed with angles of attack (AOA) from 0 to $10^{\circ}$ has been investigated for air with standard properties and velocity $50 \mathrm{~km} / \mathrm{h}$ which is nominal flight velocity for annalysed aircraft. The obtained results are presented in figure 3 .

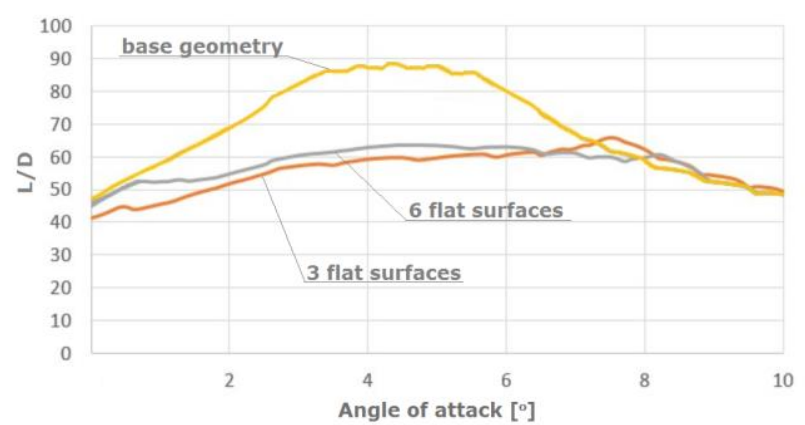

Fig. 3. Lift to drag ratio for base geometry and its modifications with 3 and 6 flat surfaces.

It is clearly visible that the modified geometries have lower values of lift to drag ratio especially for angles of attack lower than $7^{\circ}$. The optimal angle of attack for base geometry is $4.4^{\circ}$ whereas for modified airfoils this value is translated to higher angles of attack (see table 1) so the lift to drag ratio decreases.

Table 1. Optimal angles of attack and lift to drag ratio values for examined geometries

\begin{tabular}{|c|c|c|c|}
\hline Parameter & $\begin{array}{c}\text { Base } \\
\text { airfoil }\end{array}$ & $\begin{array}{c}\text { Airfoil } \\
\text { with 3 flat } \\
\text { surfaces }\end{array}$ & $\begin{array}{c}\text { Airfoil } \\
\text { with 6 flat } \\
\text { surfaces }\end{array}$ \\
\hline $\begin{array}{c}\text { Optimal } \\
\text { AOA }\end{array}$ & $4.4^{\circ}$ & $7.5^{\circ}$ & $8.2^{\circ}$ \\
\hline L/ D & 88.02 & 63.58 & 59.59 \\
\hline
\end{tabular}

Any of this modifications is not beneficial from aerodynamic point of view, so the wing profile cannot be flatted. This forces application of flexible photovoltaic cells which may be adjusted to the wing shape.

\subsection{Power system}

The energy source in analysed case is made of photovoltaic cells Sun Power $3^{\text {rd }}$ Generation which properties are presented in table 2. The dimensions of single cell are presented in figure 4, and its mass is equal $6.5 \mathrm{~g}$, so the power is $139 \mathrm{~W} / \mathrm{m}^{2}$ and $591 \mathrm{~W} / \mathrm{kg}$. In comparison to similar solutions, the Sun Power cells have more beneficial parameters converted to units of mass and area. Power system of the aircraft must ensure the proper amount of energy mainly for electric engine AXI $2830750 \mathrm{~W}$, flight control system and other onboard devices. Based on the energy consumption of each component, the previous experience, it was established that the average consumption of electric power is about $30 \mathrm{~W}$.
Table 2. Specification of Sun Power $3^{\text {rd }}$ Generation photovoltaic cells [12]

\begin{tabular}{|c|c|}
\hline Parameter & Value \\
\hline Power & $3.84 \mathrm{~W}$ \\
\hline Efficiency & $24.8 \%$ \\
\hline Voltage at MPP & $0.634 \mathrm{~V}$ \\
\hline Current at MPP & $6.06 \mathrm{~A}$ \\
\hline Voltage at open circuit & $0.724 \mathrm{~V}$ \\
\hline Current at short circut & $6.43 \mathrm{~A}$ \\
\hline
\end{tabular}

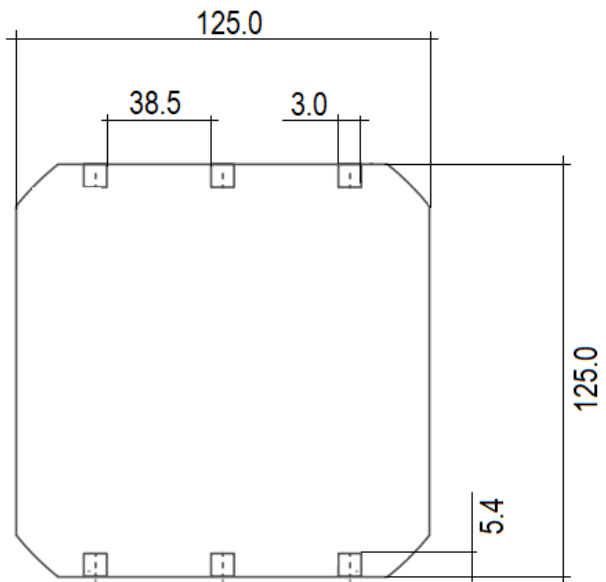

Fig. 4. Main dimensions of Sun Power $3^{\text {rd }}$ Generation photovoltaic cell.

To provide the energy at night and days with insufficient irradiance, the battery storage system is implemented. Firstly, there were considered lithium-ion and lithiumpolymer batteries, between which the main difference is the type of electrolyte, respectively liquid and solid [13]. The energy storage system in analysed case is made of Li-ion SAMSUNG INR 18650-35E batteries which properties are presented in table 3 [14].

Table 3. Specification of SAMSUNG INR 18650-35E battery

\begin{tabular}{|c|c|}
\hline Parameter & Value \\
\hline Capacity & $3500 \mathrm{mAh}$ \\
\hline Nominal Voltage & $3.7 \mathrm{~V}$ \\
\hline Standard charge current & $1700 \mathrm{mAh}$ \\
\hline Maximum Charge Voltage & $4.2 \mathrm{~V}$ \\
\hline
\end{tabular}

The dimensions of cylindric battery are: $18.2 \mathrm{~mm} \times 65.0$ $\mathrm{mm}$ (see figure 5.) and its mass $48.0 \mathrm{~g}$, so the capacity is $270 \mathrm{Wh} / \mathrm{kg}$. 


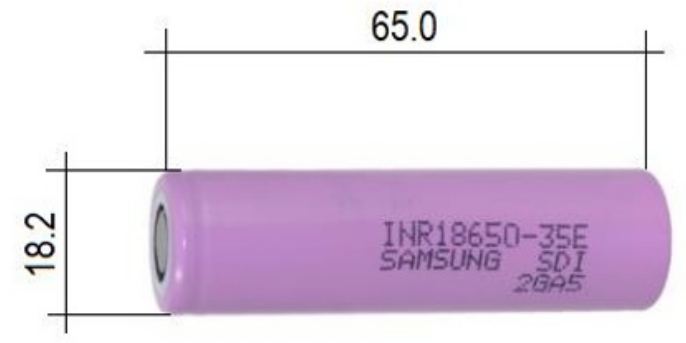

Fig. 5. SAMSUNG INR 18650-35E battery with dimensions.

To estimate the number of this batteries which can provide energy supply the following assumptions have been made: time without sun irradiance 9h, discharge about $90 \%$ [15] and energy consumption $30 \mathrm{~W}$. This allowed to calculate the energy which must be stored in batteries: $300 \mathrm{Wh}$. One battery can store 12,95 Wh of energy, so there is need to implement 24 batteries. For safety reasons, 4 additional units were added. The whole storage system consists of 4 groups connected in serial. In single group there are 7 batteries connected parallel. To ensure that the energy system works with maximum efficiency two management systems were implemented: Maximum Power Point Tracking (MPPT) and Battery Management System (BMS). The first one is responsible for maximum production of electricity from photovoltaic panels, the role of the second system is to balance the energy between load and storage system.

\section{Model in TRNSYS}

The model of energy system of solar-powered aircraft has been prepared in TRNSYS software (figure 6).

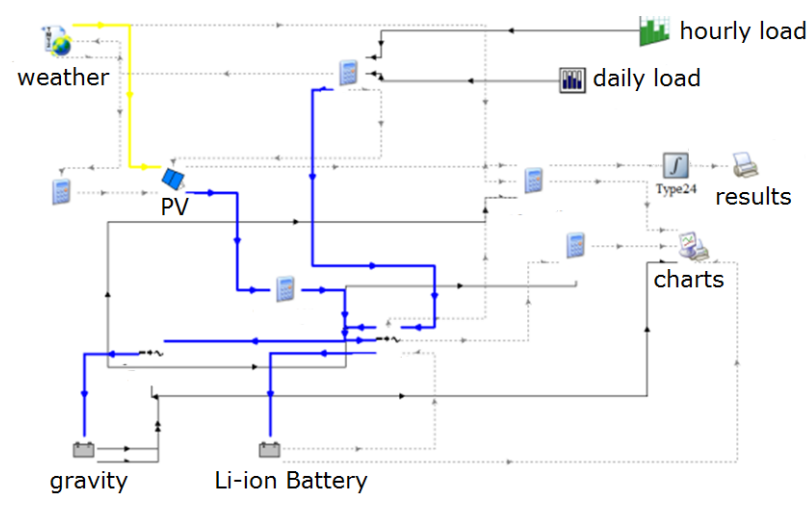

Fig. 6. Scheme of energy system in solar-powered plane designed in TRNSYS.

It consists of weather element (type109) responsible for temporary weather conditions from Meteonorm data base. Data about irradiance, ambient temperature was transfered to PV panels which parameters were set in accordance to table 2. The information about amount of solar energy converted into electricity was directed to energy storage system (type 47a) based on Li-ion batteries. Moreover, the gravitational energy was modelled. The usage of electric engine which powers the plane was set by hourly and daily diagrams. Other elements of model scheme are responsible for unit conversion, calculation and presentation of obtained results.

\section{Results}

The dynamic simulations were carried out for six months with assumption that the enginee works 5 minutes every hour, in meantime the plane is gliding. The energy balance chart (Fig.7) for each month shows insufficient amount of energy in Jnuary and November - the whole energy produced by PV cells is used to power the engine, so the batteries are not charged.

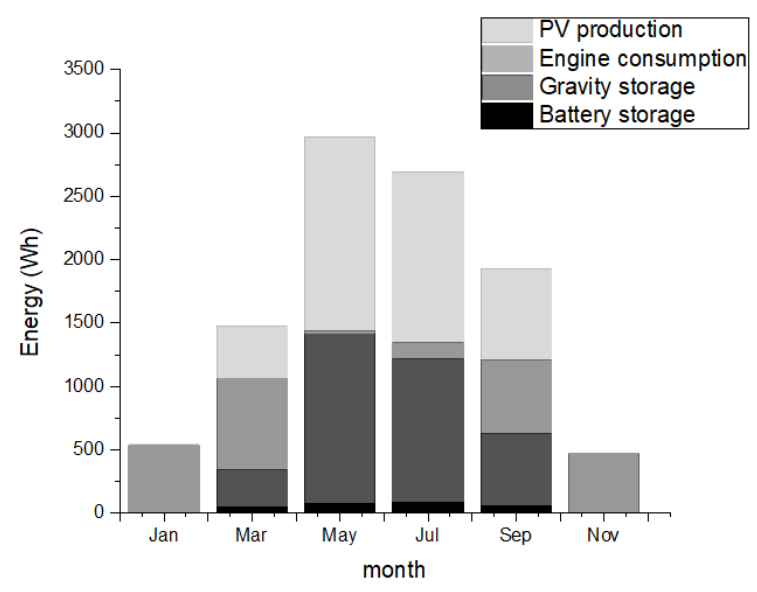

Fig. 7. Energy balance of solar plane power system

Therefore the day and night flight is impossible in late autunmn and winter months. The most beneficial conditions for flight are noticed in May. In this month nearly half of the produced energy is used by engine, similar amounnt of energy is converted into potential energy (gravity storage).

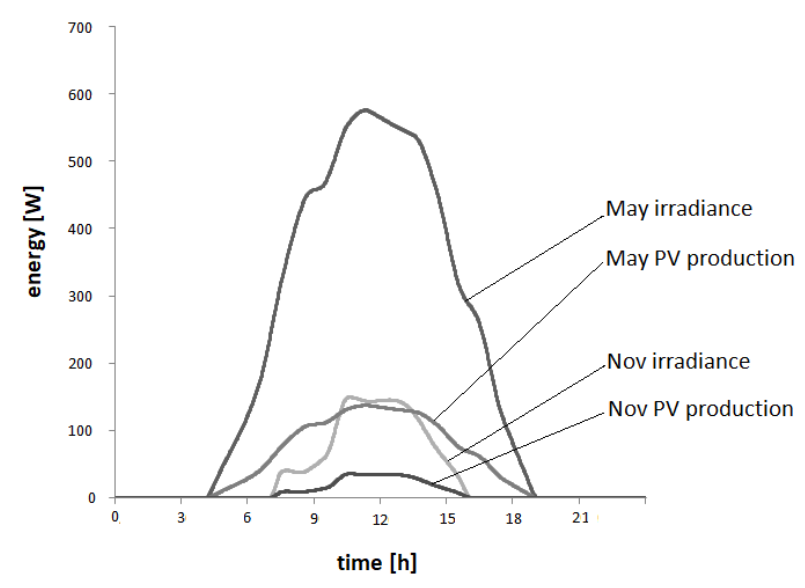

Fig. 8. Comparison of irradiance and production of electricity in May and November.

The months with the most and least favorable conditions (respectively May and November) has been analysed in 
more detailed way. The maximum irradiance during exemplary day in May is about 4 times higher than in November (Fig. 8). What is more, the time with sunlight in May is about $15 \mathrm{~h}$ whereas in November it is only $9 \mathrm{~h}$. Figure 9 presents the energy charging and discharging cycle. The level of battery power drastically decreases when the enginee is activated. The more energy produce the PV system, the smaller amoyunt of energy is taken from storage system.
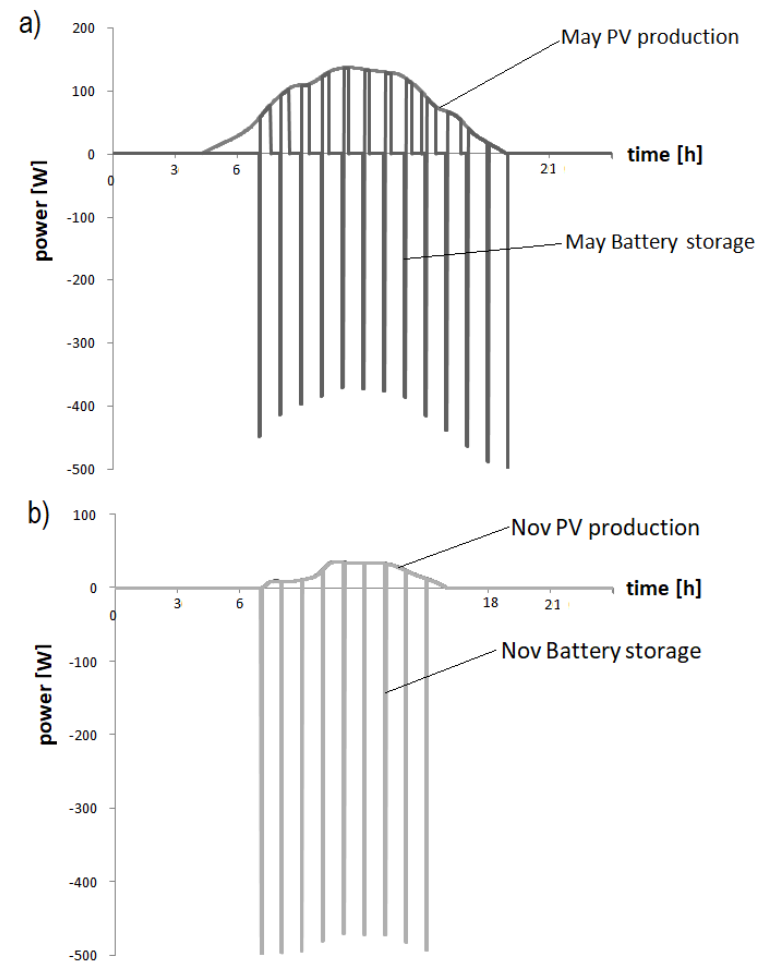

Fig. 9. Comparison of irradiance and battery storage in a) May and b) November.

\section{Conclusions}

The analysis that have been presented in this paper shows that the modification of airfoil shape in order to place flatly the photovoltaic cells is not beneficial. It is due to significant losses in lift force and increase in drag which can not be balanced by higher electrical efficiency. The flexible photovoltaic cells must be used. The results of simulations carried out in TRNSYS prove that the solar energy can be used as a power source in analysed airplane in spring and summer months. Disparity in monthly irradiance is crucial for vehicles powered by solar energy, because to all day long operation in autumn and winter, the additional batteries should be added. This is inconvenient because of increase in construction mass. Nevertheless, the continuous operation of solar plane in current state is possible during sunny days.

\section{References}

1. Em. Kostopoulos, G. Spyropoulos, K. Christopoulos, J.K. Kaldellis, Solar energy contribution to an electric vehicle needs on the basis of long-term measurements, Procedia Structural Integrity 10 (2018) 203-210

2. Antonio García-Olivares, Jordi Solé, Oleg Osychenko, Transportation in a $100 \%$ renewable energy system, Energy Conversion and Management 158 (2018) 266-285

3. Galiveeti Hemakumar Reddy, Arup Kumar Goswami, Nalin B. Dev Choudhury, Impact of plug-in electric vehicles and distributed generation on reliability of distribution systems, Engineering Science and Technology, an International Journal 21 (2018) 5059

4. Mohamed Nadir Boukoberinea, Zhibin Zhoub, Mohamed Benbouzid, A critical review on unmanned aerial vehicles power supply and energy management: Solutions, strategies, and prospects, Applied Energy 255 (2019) 113-123

5. Zhu, Zheng Guo, Zhongxi Hou, Solar-powered airplanes: A historical perspective and future challenges, Progress in Aerospace Sciences 71 (2014) 36-53

6. Boucher RJ, Sunrise, the World's first solar-powered airplane, Journal of Aircraft 1984; 10 (22): 840-846

7. Boucher RJ, History of solar flight, AIAA/SAE/ASME 20th Joint Propulsion Conference. Cincinnati, Ohio, AIAA 1984:84-1429

8. Dawson D., Solar Impulse 2: Pulse on the future, Composites World 05 (2016) pp. 48-49

9. Safyanu Bashir Danjuma, Zamri Omar, Mohd Noor Abdullah, Review of Photovoltaic Cells for SolarPowered Aircraft Applications, International Journal of Engineering \& Technology, 7 (4.25) (2018) 131135

10. Mingjian Wu, Zhiwei Shi, Tianhang Xiao, Z.L.J. Chen, Haisong Ang, Effect of solar cell efficiency and flight condition on optimal flight control and energy performance for Z-shaped wing stratospheric solar aircraft, Acta Astronautica 164 (2019) 366-375

11. S.A. Klein, J.A. Duffie, J.C. Mitchell, J.P. Kummer et al, TRNSYS 17 Volume 1 Getting Started, Solar Energy Laboratory, University of Wisconsin Madison, 2009, p. 9, 30-37

12. Sunpower solar cells website: us.sunpower.com, datasheets of product, last access : 1st of December 2019

13. Pistoia G. Gianfranco P., Lithium-Ion Batteries: Advances and Applications, Elsevier eBooks (ICM), 2014

14. Website of batteries store : www.hurt.com.pl/akumulator, datasheets of product, last access : 1st of December 2019

15. Malcolm R. Perdontis, Battery Manufacturing and Electric and Hybrid Vehicles, New York: Nova Science Publishers, 2011 